\author{
Mateusz MACHAJ, PhD \\ Institute of Economic Sciences, University of Wroclaw \\ e-mail: mateusz.machaj@uwr.edu.pl \\ ORCID: 0000-0002-1497-782X
}

DOI: $10.15290 /$ oes.2018.04.94.12

\title{
SOCIALIST CHALLENGE: CALCULATION OR CONTESTABILITY?
}

\begin{abstract}
Summary
Due to the recent discussion in the Review of Political Economy there was observed the reignited debate on the nature of the socialist system and economic calculation challenge [Denis, 2015; Bylund, Manish, 2017]. In the paper I will not discuss directly the theses of both sides. I will attempt to show their polemic results of the ambiguity of the initial calculation argument [Mises, 1990]. It appears that the argument against the possibility of socialism could be called "the contestability argument" rather than "the calculation argument". The goal of this paper is to reformulate the initial argument about the economic rationality of socialist projects.
\end{abstract}

Key words: socialist calculation debate, markets, economic systems, contestability, calculation

JEL classification: B13, D02, P51

\section{Introduction: The new contestation of the argumentation concerning economic accounts in the socialism}

It may appear that it would be difficult to find a more closed subject than the problem of economic effectiveness in socialism. However, as discussion presented in the Review of Policitcal Economy shows, in economics none of the subjects may be considered as a closed one. It is the case with the bankrupt idea of the effective socialist planning. However, once again there was presented such argumentation that may be considered as the new contribution to the debate.

A. Denis [2015] emphasized that the problem of economic calculation in socialism, which was primarily presented by Mises, took place in accordance with the straight linear argumentation: private ownership enables the exchange; as the result of the exchange there are developed commercial transactions which are characterized by interchangeable relations between goods (prices); meanwhile prices enable making calculations. i.e. making the indispensable economization of production factors. According to Denis, while the reasoning is presented correctly, it is not the only possible scenario of making the calculation of money (the analogous argumentation is present also in the following publication: [Lange, 1936, pp. 54-55]). Private 
ownership may result in the achievement of this goal, but it is possible also thanks to the hybrid of private and public ownership where management takes place in a more competitive way. This would mean the existence of trade relations between various public entities that further on would set the prices necessary for the realization of effective calculation (by means of their transactions).

In response to this view, Bylund and Manish [2017] in fact do not attack directly the argumentation of Denis, but point to the fact that public management within several property (which was discussed by Denis) will be ineffective because it does not present any characteristics of private ownership. Meanwhile, Bylund and Manish focus on the literature concerning corporation governance and the effectiveness of the way markets are solving the principal-agent problem.

Before I will reply to the main argumentation of both sides of the dispute, I will present a slightly different perspective (than those represented by the dispute participants) of the very phenomenon of economic calculation which (in my opinion) will enable one not only to understand the messages from the Authors, but also to notice the power and correctness of the argumentation in both cases.

\section{Why calculation instead of technology?}

The original argumentation of Mises [1990] was presented as a relatively simple linear explanation starting from the ownership rights to prices in monetary terms resulting from the exchange of these titles of ownership. Twenty years afterwards Mises began his work on the economic treaty where he analyzed the issues of calculations and the process of valuation [Mises, 2007]. It enables one to understand better the meaning of the original argument. Attention ought to be drawn to the rather depreciated statements of Mises who ponders over whether in economy it is possible to do without monetary calculation and, instead of it, use other activity criteria: The mere information conveyed by technology would suffice for the performance of calculation only if all means of production-both material and buman-could be perfectly substituted for one another according to definite ratios, or if they all were absolutely specific. In the former case all means of production would be fit, although according to different ratios, for the attainment of all ends whatever; things would be as if only one kind of means-one kind of economic goods of a higher order existed. In the latter case each means could be employed for the attainment of one end only; one would attach to each group of complementary factors of production the value attached to the respective good of the first order [Mises, 1998, pp. 207-208].

In the aforementioned words Mises admits that hypothetically there is possibility of technological calculation in the world of the ideally non-specific production factors. Then in fact there would occur only one category of capital good, one type of high level good. It could be accounted for in accordance with one selected natural unit, for example in kilograms. In such situation each production process could be measured in terms of such kilograms. In this hypothetical scenario there would be a possibility of natural calculation that would directly express the technological limitations. 
Naturally, there would remain also the issue regarding the priority of the values of final goods, which is the subject of separate deliberations. The specification of it is connected with other challenges of socialism that have more ethical, political and sociological character (problems with organizing the consumer market require separate analysis). However, assuming that such prioritizing becomes settled, in case of the hypothetical condition of Mises, the calculation is becoming solely a technological problem because each of the desired processes will be realized in order to minimize the kilograms of one capital good.

In the aforementioned quotation Mises goes further and in fact does not mention solely one capital good. Mises stresses that hypothetically there could be a plenty of these goods, but the specification of changeability in certain proportions would be essential. It means that calculation without a market would be possible not only in case of the heterogeneous character of capital (homogeneity enables the creation of a calculation unit). Calculation without a market would be possible as well if the interchangeability of production goods was perfectly settled.

Using the language of technical economics, Mises states that if all the production functions were familiar and these functions were settled in relation to one another in the way that enables the specification of the marginal rates of transformation of production factors, calculation without a market would be possible. Exactly the same statement (but expressed in a different way) was included by Hayek in his elaborations. As regards the series of assumptions: if we know all the needs and their hierarchical order, if we know the available production factors, if we know the marginal rates of substitution, there remains the purely "logical" problem ${ }^{1}$ [Hayek, 1945, p. 519].

In fact, all the calculations aim at specifying the tradeoffs. ${ }^{2}$ In order to make the "optimum" selection in certain conditions, it is necessary to notice other paths of acting and then combine them. It is possible when there is only one capital good: the less kilograms of it will be used, the better (if this good is heterogenous and one kilogram does not equal to another one, then one does not see one good). What does the situation look like when there are various capital goods but with precisely specified alternative case?

Let us take as the example the simple case of Cobb-Douglas function. There are two production factors, capital goods and work: man hours and machine hours. Although there are two units in the model, it is possible to specify with simplicity their mutual flexibility and interchangeability. It is a well known fact that production will be affected by reducing the input of one machine hour and replacing it, for

1 The term "logical" does not appear to be particularly adequate. Most probably it regarded the pure logic of choice.

2 For Hayek, the issue of discovering such alternatives becomes crucial in the arguments regarding the functioning of socialism. An important element in the light of it becomes the issue of knowledge and lack of knowledge that market entities have about the world. Thus Hayek slightly modifies Mises's starting point from the uncertainty about the world. Uncertainty is expanded owing to the ignorance of still unrecognized alternatives of acting (I express my gratitude to an anonymous reviewer for making such comment). 
example, by one man hour. The effect does not necessarily need to be linear because the function may be clearly more complicated. However, having them at full disposal and for analysis, one may observe that, for example, production will be affected by the resignation from the tenth man hour that is replaced by the twentieth machine hour.

In this way - even though apparently there are different heterogenous units they may be easily homogenized when they are reduced to one common denominator: their final influence on the end value of production. Mises had such intention when he wrote that theoretically various capital goods could be reduced to one denominator as if they constituted just one capital good. In this scenario the calculation could be made entirely by means of purely technological deliberations.

As the consequence there arises the following question: Why such calculation may not be made? It is due to the fact that we are incapable of specifying such alternative possibility. Hayek [1945] analyzed these more thoroughly and claimed that the knowledge of alternative possibilities may not be centralized. Naturally, in certain degree this assumption may be true, but at the same time one needs to remember that there are such alternative possibilities that are available solely to central entities (for example, those using the effect of scale). However, the lack of alternative possibility does not appear to result chiefly from the fact that the knowledge of it is decentralized, but from the fact that the world as such is heterogenous and complicated, while its nature is constantly discovered and changed by the active man. What is more, there is no guarantee that even when all the possible functions of production are familiar for us, we will be able to solve them using calculations (in terms of complexity there may be problems).

\section{Market calculation as the instrument of contestability}

Since technological calculation is impossible for many reasons (owing to the fact that capital goods are not ideally non-specific with certain alternative possibility, etc.) it is necessary to use one of its substitutes: it is calculation in monetary units. They are the same as those used when goods on the market are acquired by consumers that in this way set the relative prices of these goods. From them there begins the imputation of prices backwards on the value of production factors used for creating them.

Where do these backward prices on production factors come from and what is their value? In fact, they may have no origin and their value may be arbitrary. It should be stated in a reasonably honest way: prices constitute the effect of the decision of the entity that sets them. The issue of which production factor has a certain monetary value is in the hands on someone who will fix it in the adopted scheme.

Therefore, where is the meaning of the calculation inside a market project that was described by Mises? Above all - in the market character of this calculation. Within the socialist planning a party may realize the price imputation [Cole, 1971, 
pp. 183-185]. Additionally, it may decide that a particular factor has a certain value and may draw attention to the values on the final markets. However, this is the monopolistic decision and it is not subject to any doubts in terms of the competition. In case of a market project there is constant contestability of the present prices. Markets are contentious - according to Baumol [Baumol et al., 1982]. Each valuated production factor has a certain price that results from the agreement between the sides of the contract that is most frequently rooted in the conditions of the direct future. However, this is the price that may be contested and easily questioned by other market participants from both sides of the transaction.

In this particular way competition in the market is becoming at the same time the way of economizing entrepreneurial skills by means of the signalized money calculation. An entrepreneur realizing one of the economic projects in a certain area (by renting an area for this purpose) must overbid the competitive offers of other originators that are willing to make use of the production factor. The same principle is in force not only as regards land and real estate, but also labor markets, semiproducts and other capital goods.

Monetary calculation is not perfect since it always leads to the most optimal results. It does not reflect the hypothetical homogeneity of all the production factors nor does it aim towards any imaginary "technological optimum". It is simply the only available instrument that is used in order to economize the imputation skills of the entrepreneurs that do not achieve consensus on the following dilemma: which production methods as the best (either most economical or increasing the final value for the consumers).

In the market system the calculation is used as the instrument that confronts the opinions of various competitive entrepreneurs. In the socialist system it is possible to use also monetary calculation, but it will not express the contestability opinions of various rival entrepreneurs (but the decisions of the authorities). Therefore, in contrast to the opinion expressed by Mises, in socialism there is no shortage of calculations. Calculation occurs there, but it takes place in an entirely different way. This way does not exclude productive entrepreneurs from the economic process nor does it force them to function in accordance with other rules that are characteristic for parties. Nothing stops political authority from ascribing monetary features to all the production factors. However, these settlements have completely different economic importance than the settlements made by market entities within the freedom of contracts.

\section{Mono property, poly property, private property, national property and market socialism}

The aforementioned deliberations have impact on the discussion led by Denis and also by Bylund and Manish. In fact, both sides have a point in their opinions. The viewpoint expressed by Denis is consistent with the reasoning of Mises, in particular in the context of his first answers to the original argumentation in the 
1920s written in German language. In response to Polanyi's [1922] theses regarding the possibility to introduce a corporation within a syndicalist order, Mises underlined that this project is not strictly socialistic owing to not being connected solely with a party - and in fact with only single property [Mises, 2002, p. 356]. In the syndicalist scheme there occurs several property which - as it was stated in the primary argument - opens the path to the interchangeable relation in money, i.e. as the consequence - to the money calculation. Naturally it does not mean that syndicalism may be an efficient system, but Mises claims that in such situation this system is different from the socialist system and as such it requires separate opinion. Therefore, Denis appears to be right to the point and indicates the same as Mises: in the situation of poly property there is the possibility of the formation of interchangeable relations with regards to the possessed titles of ownership (by collectives). Therefore, private ownership is one of the variants of poly property that enables calculation, but it is not the only possible variant.

Meanwhile, following this example, one may conclude that "calculation" occurs also in the system of mono property, even in the situation of establishing one socialist owner. However, it is essential that this type of calculation fully expresses the will of one owner. When poly property is introduced in the system, calculation is the effect of a bargain between several owners. In this way calculation begins to express more than one will and it is made in accordance with specific game rules (the system of law). In this situation one may observe that in contrast to the intentions expressed by Mises and to the attempt to settle one strict border line, the deliberations regarding syndicalism are very close to socialist ideas when the economic calculation is taken into consideration The discussion regards in fact the following question: who has the right to decide upon the economic process and in what way should it be done? In what way are the decisions made? What spectrum of activities is possible during their realization?

Using analogy, Bylund and Manish also have a point when they state that even if there is formed poly property and there is opened a path to any form of calculation, at the same time the major part of the economic system may be excluded from the competition process. For example, there may disappear both capital markets that establish the rules of economizing capital and very important manager markets enabling independent evaluations of the economic activities of the leaders. Then the problem does not lie in the lack of calculation, but in the lack of entrepreneurial evaluation connected with the respect for property rights

In the Review of Political Economy exchange constitutes not only the return to the sources of the calculating argument, but it is also the echo of Oskar Lange's project of market socialism [1936]. Lange's aim was the conceptual defense of the possibility of making calculation and at the same time introducing certain competition elements into the socialist system. Economic projects would be realized by the managers of public enterprises. In this position one may notice one essential problem with this project. It is still not settled to what degree such order may be contested. It is possible to assume securely that the managers of public enterprises in market socialism do not have such freedom as private owners (in such case 
market socialism would not be different in any way from the capitalism). For that reason they remain limited by political recommendation on what, when and for whom they ought to produce despite the fact that in Lange's scheme there are formed centralistic price parameters that in a bureaucratic way evaluate the efficiency of their activities. Perhaps a certain degree of their autonomy is possible, but at the same time they are directly subordinate to political bodies, instead of private owners that compete with one another.

\section{Conclusions}

The debate on the economic account in the socialism constantly ignites the discussion not only owing to the controversial character of the socialist project, but also due to the fact that many conclusions related with it are important for the economic comparison of various systems (not only the socialist system). The recent discussion between Denis and Bylund, Manish ought to be evaluated in a similar way. As a matter of fact, they discussed the nature of public property and the effective mechanisms in the control of company management. These deliberations were surrounded by the concept of economic calculation as the main socialistic problem.

Meanwhile, in the paper I attempted to show that it is better to understand economic problems as not only calculations as such, but as the challenges regarding alternative possibilities. It regards the specification of a certain standard of exchanging the ways of realizing the objective that are competitive towards each other. Then it is possible to see that the main problem of socialism results from the impossibility to contest it, i.e. from the compulsory political dictatorship where all the plans (also the economic ones) are not subject to competitive verification in the competitive market surrounding. In other words, alternative possibility in socialism is imposed by political authority, not by market competition. This alternative possibility may not be contested (state) in contrast to the alternative possibility that may be contested (market).

\section{References}

Baumol W., Panzar J., Willig R., 1982, Contestable Markets and the Theory of Industry Structure, Harcourt Brace Jovanovich, New York.

Bylund Per L., Manish G.P., 2017, Private Property and Economic Calculation: A Reply to Andy Denis ,"Review of Political Economy", vol. 29(3).

Cole G., 1971, Economic Planning, Kennikat Press, New York.

Denis A., 2015, Economic Calculation: Private Property or Several Control, "Review of Political Economy", vol. 27(4).

Hayek F.A, 1945, The Use of Knowledge in Society, "American Economic Review", vol. $35(4)$. 
Lange O, 1936, On the Economic Theory of Socialism: Part One, "Review of Economic Studies", vol. 4(1).

Mises L., 1990, Economic Calculation in the Socialist Commonwealth, Ludwig von Mises Institute, Auburn, Alabama.

Mises L., 1998, Human Action. A Treatise on Economics, Mises Institute, Auburn, Alabama.

Mises L., 2002, New Contributions to the Problem of Socialist Economic Calculation, [in:] Selected Writings of Ludwig von Mises. Between the Two World Wars: Monetary Disorder, Interventionism, Socialism, and the Great Depression, Ebeling R. (ed.), Liberty Fund, Indianapolis, Indiana.

Polanyi K., 1922, Sozialistische Rechnungslegung, "Archiv für Sozialwissenschaft und Sozialpolitik", vol. 49(2). 